\title{
CAPITAL MARKET COINTEGRATION OF OLD AND NEW EU MEMBER STATES
}

\author{
Tonci Svilokos* \\ Keywords: cointegration, financial crisis, VAR, capital market, \\ $C E E$ \\ JEL: E22, O16
}

\begin{abstract}
The author investigates the degree of capital market cointegration of old and new EU member states, and examines whether, and to what extent, the global financial crisis had an effect on it. Capital markets are completely integrated if assets of equal risk have identical expected returns, irrespective of the location of the capital market. Therefore the risk that the investor agrees to take in the integrated international market is the result of common factors and it is not possible to diversify the risk. The degree of financial integration of capital markets can be determined by analyzing the movement of market indices. In this paper the multivariate $\operatorname{VAR}(5)$ econometric models were set up and tested in order to analyze the multilateral integration of selected capital markets of developed European countries (Britain and Germany) and selected - new EU member states (Slovakia, Czech Republic, Slovenia and Hungary). Input data of
\end{abstract}

*University of Dubrovnik, Department of Economy and Business Economy, Lapadska obala 7, 20000 Dubrovnik, Phone: +385(20)445929 Fax: +385(20)356060, E-mail address: tonci.svilokos@unidu.hr 
the model are daily stock market indices (FTSE, DAX, BUX, SAX, PX and SBI20) for the time period January 2001 to October 2009. The study was conducted in three stages: In the first stage each series index was tested for the presence of unit roots, in order to determine whether the time series was stationary or not (to do this, ADF and Phillips - Perron tests were used). In the second stage multivariate VAR(5) models were set up, to which the Johansen method for determining cointegration was applied. In the third stage of the research process, the dynamics of the integration of underlying capital markets was determined by calculating the relevant $\lambda_{\text {trace }}$ value and dividing it by the critical $\lambda$ value.

\section{INTRODUCTION}

The issue of cointegration between equity markets has recently attracted the attention of many researchers and investors. The reason is that the degree of integration affects the possibility of portfolio diversification in investment activity in various capital markets, in order to avoid country specific systematic risk. As capital markets are increasingly integrated, the effect of diversification is reduced.

Consequently, because of the relatively low degree of cointegration of emerging capital markets (such as the Slovenian, Hungarian, Czech Republic and Slovak markets) with developed capital markets before joining the EU, investors from developed countries have often chosen diversification in these emerging markets. Before the global financial crisis, relatively high returns also attracted investors to these new markets, but they always took into consideration the higher risks associated with markets that are based upon transitional economies.

Because of the increased number of linkages between the economies of "old" and "new" EU countries, one can expect that the degree of cointegration of their markets should also increase, which, as noted above, reduces the benefits of diversification, and in turn leads to the disappearance of a substantial motive for investing in those markets. Of course, in the opposite, encouraging, it is increasing the prospects for economic growth in CEE countries arising from their integration into the EU economy.

Tonci Svilokos - CAPITAL MARKET COINTEGRATION OF OLD AND NEW EU MEMBER STATES 
Increased equity market co-movements can arise from increased international trade, increased capital mobility, reduction of controls on international capital movements, as well as the various forms of policy alignment associated with the creation of economic unions. Events such as the harmonization of monetary and fiscal policies, as well as the introduction of the euro, contribute to the EU capital markets becoming more integrated. There is a wide range of literature that attempts to assess the impact of introducing the euro on the interrelationships of various financial markets (Hardouvelis et al., 1999, Syriopoulos, T. 2007, Fratzscher, M., 2001, Kim et. al., 2005) which often show an increased degree of integration after the advent of the euro.

Furthermore, the effects of the global financial crisis have been particularly devastating for many newly emerging markets, which also substantially reduce the interest of foreign investors for investments in these markets (see Figure 1). That is supported by the following facts: SBI20 and BUX indices dropped their value by about 68\% from July 2007 to March 2009, and the Prague Stock Exchange index (PX) dropped its value even more (91\%) for the same period. Of course, the developed stock markets suffered a huge loss as well. The FTSE index in the same period decreased by about $43 \%$, and the DAX index of the Frankfurt Stock Exchange by about 51\%. The smallest reduction of its index value was reported by the Slovak Stock Exchange (31\%), but this stock exchange has ultimately entered the downward trend, and there is no sign of its stopping that fall. The turnover and market capitalization of the CityplaceBratislava stock exchange in relation to the Slovak economy is very low, which must also be taken into consideration (see Table 1).

This paper examines the degree of capital market cointegration of old and new EU member states, and investigates whether the global financial crisis had a significant effect on this. The author examines the movement of capital market indices of the selected sample of new EU member states (Slovenia, Czech Republic, Hungary and Slovakia) in relation to the movement of the capital market indices of selected developed European countries (Germany and Great Britain). The rest of the paper is organized as follows: the second part gives a brief review of papers dealing with relevant issues; the third part presents the econometric 
methods used in empirical research, and descriptive data analysis; the fourth part contains the results of the empirical research. And finally the fifth part offers some concluding remarks in which it is considered whether the results are in line with expectations based on economic theory.

\section{LITERATURE REVIEW}

There are numerous scientific articles that explore the connections between capital markets. Different approaches were employed in the investigation and various results were obtained. Diverse aspects of equity market relationships have been investigated, including volatility spillovers across markets, market correlation structures, and financial crisis contagion. From the entire range of papers, the seminal work of Engle and Granger (1987) and Johansen (1988), should be emphasized, in which, for the first time, cointegration methodology was applied to test the joint movements of capital markets. That methodology is also used in this paper.

Most previous studies have dealt with the cointegration of developed capital markets. Developed European capital markets are investigated by Fratzscher (2001) who employed a trivariate GARCH model with time-varying coefficients for a set of 16 countries, 11 of them from the European Union. He discovered a high degree of financial integration amongst European equity markets since 1996.

Beside Fratzscher, Kim, Moshirian and Wu (2005) also dealt with these markets. They investigated the impact of the EMU on the dynamic process of the integration of selected developed EU countries, using a bivariate EGARCH framework with time-varying conditional correlations. They found unidirectional causality, and concluded that the EMU has been necessary for stock market integration. In more recent studies, researchers, encouraged by the waves of EU enlargement, have chosen the links between capital markets of old and new EU member states or candidate states as a research topic. The work of Koèende and Egert (2007) stands out, in which the authors, using 5-minute tick intraday price data of various stock market indices, did not find any robust cointegration relationship 
for any of the stock index pairs or for any of the extended speci?cations. However, they found some signs of short-term spillover effects both in terms of stock returns and stock price volatility.

Gilmore, Lucey and McManus (2008) published a paper in which both static and dynamic methods of analysis were applied. Static analysis has shown relatively low levels of short-term correlation as well as a lack of statistically significant cointegration. On the other hand, dynamic analysis showed a slightly more complex picture of the unstable short-run correlations and long-run cointegration with breaks, which is fairly surprising when the strong trade ties between the EU countries and the decade-long process of alignment of CEE countries, both in political and in economic conditions, with the rest of the EU is taken into consideration.

In their work Vizek and Dadiæ (2006) explore the bilateral and multilateral integration of capital markets of selected Central and Eastern European countries including Croatia and the German capital market. This paper is particularly interesting because it extends the research to a candidate country for EU membership (Croatia), which has strong economic relationships with the European Union. Although bilateral integration between the studied markets was not found, because of the results of the multilateral integration test, the authors concluded that the forces driving the integration were quite powerful and they expect capital markets to move further towards more complete integration, especially after the countries of Central and Eastern Europe join the European Monetary Union.

Regarding the papers that explore the integration of capital markets in Asia, it is worth mentioning the work of Yu, Fung and Tam (2010) who found that after a slowing down between 2002 and 2006, the equity market integration process picked up again in 2007-2008. However, as these authors said, the integration process for the Asian equity market certainly was not complete.

In addition to this group of papers, the work of Dekker, Sen and Young (2001) should be distinguished, which confirms earlier studies that show the AsiaPacific region to be characterized by informationally efficient equity markets, with a number of these markets showing strong linkages. 
The study of Sharma and Wongbangpo (2002), which analyzes the degree of long-term and short-term co-movements in the stock markets of five ASEAN countries, reveals that four out of the five capital markets show a long-term cointegration, which is in line with the above mentioned works of the Asian region.

This review of the relevant literature is certainly not comprehensive, because of the large number of papers dealing with this issue, but these are, according the author, the most current and most prominent articles.

\section{METHODOLOGY AND DATA}

\subsection{METHODOLOGY}

If two or more series are cointegrated, it implies that they have a long-run equilibrium relationship, with possible occasional deviations from this equilibrium in the short-run. For example, spot and futures prices are essentially prices of the same asset but with different delivery and payment dates. From these facts the financial theory suggests that these series should be cointegrated, and means that they contain a common stochastic trend. If these series separate from one another, theory says that the effect of market forces will bring them back to follow their long-run relationship.

The capital markets cointegration test is based on the very same concept. The test is carried out by investigating the cointegration relationships between series of various stock market indices. There are (at least) three methods that could be used: Engle-Granger, Enle-Yoo and Johansen. The Johansen technique is based on the concept of weak form or covariance stationarity, therefore its definition follows below.

Weak stationarity of time series means that the time series has a constant mean, a constant variance, and that the covariance between two time periods depends only on the interval, and not the timing ${ }^{1}$. The importance of stationarity of

\footnotetext{
${ }^{1}$ This means that the covariance between yt and yt-1 is the same as the covariance between
} 
time series is reflected in the possibility of generalisation of dynamic sample analysis to a whole population in order to make forecasts. Using non-stationary series can lead to spurious regressions. If the variables employed in a regression model are not stationary, then it can be shown that the standard assumptions of analysis will not be valid. In other words, classic t-ratio will not follow $t$ distribution and the classical F-ratio will not follow the $F$ distribution, etc (Brooks, C., 2002, 368).

A test that is used for testing stationarity - Unit Root Test - was developed by Dickey and Fuller (1979). The test in its initial form was based on the following model:

$$
y_{t}=\phi y_{t-1}+\delta x_{t}^{\prime}+u_{t}
$$

Where: $\mathrm{y}_{t}$ - the value at time $t, \mathrm{y}_{t-1}$ - the value arising in the previous time point $(t-1), \phi$ - estimated parameter that is used to assess stationarity of the series, $\delta$ - estimated parameter, $\mathrm{x}_{t}$ - exogenous regressors (which may or may not appear in the model) and $\mathrm{u}_{t}$ - white noise ${ }^{2}$.

The basic objective of the test is to examine the null hypothesis $\mathrm{H}_{0}: \phi=1$. Alternative hypothesis is $\mathrm{H}_{1}: \phi<1$. If this null hypothesis is accepted, that means that the series contains a unit root, which means that it is not stationary. It also means that the variance of the series $y$ increases with time and tends to $\infty$. If you reject the null hypothesis, this means that the series is stationary.

In practice (1) is rarely used. Instead of (1) the existence of a unit root in the series is examined by

$$
\Delta y_{t}=\psi y_{t-1}+\delta x_{t}^{\prime}+u_{t}
$$

for ease of computation and interpretation. If (2) is employed instead of (1), this means that $\psi=0$ is tested, instead of $\phi=1$ (because $\psi=\phi-1$ ). The test is conducted calculating the ratio of estimated parameter and its standard error (a classical t-test):

$$
t(\hat{\psi})=\frac{\hat{\psi}}{s e(\hat{\psi})}
$$

\footnotetext{
yt-10 and yt-11, etc.

${ }^{2}$ White noise is a series that has mean 0 and variance 2 .

${ }^{3}$ The test statistics do not follow the usual t-distribution under the null hypothesis, but rather a non-standard distribution. Critical values are derived from simulations experiments.
} 
Null hypothesis (the existence of a unit root or non-stationarity) is rejected if the computed value is more negative than the critical value for a given level of significance. This model assumes that $\mathrm{u}_{t}$ are not autocorrelated, however, $\mathrm{u}_{t}$, will be autocorrelated if there are autocorrelations of the dependent variable $\Delta \mathrm{y}_{t}$. In that case, the solution is to expand the model (2) using $p$ lags of the dependent variable:

$$
\Delta y_{t}=\psi y_{t-1}+\delta x_{t}^{\prime}+\sum_{i=1}^{p} \alpha_{i} \Delta y_{t-i}+u_{t}
$$

$\Delta \mathrm{y}_{t-i}$ lags will absorb a dynamic structure that might exist in the time series variable $\mathrm{y}_{t}$. With this extension, this test statistics is called the Augmented Dickey-Filler test (ADF). The test statistics is still applied to $\psi$ using (3), and the same critical values.

Information criteria can be applied to the dependent variable in order to determine the optimal number of lags $(p)$. The three most popular information criteria are Akaike's (AIC), Schwarz's - Bayesian (SBIC) and Hannan - Quinn (HQIC) information criterion. We will use the number of lags that will minimize the value of employed information criterion.

Together with ADF, the Phillips-Perron (PP) test is also often used in practice. The PP test is based upon a somewhat more comprehensive theory of unit root non-stationarity, but it is similar to the ADF test.

In practice, many financial variables contain one unit root. They are nonstationary in their initial levels, but their differentiation usually gives stationary series. Series that are stationary in levels are said to be integrated of order 0 . This would be written $\mathrm{I}(0)$. For those that are stationary after the first differentiation, are said to be integrated of order 1 - I(1), and those series that became stationary after the second differentiation are $\mathrm{I}(2)$, etc.

The degree of stationarity is closely associated with the concept of cointegration. In most cases, if two I(1) variables are linearly combined, then the combination will also be $\mathrm{I}(1)$. If you combine the variables that are $\mathrm{I}(\mathrm{d})$ and $\mathrm{I}(\mathrm{b})$, where $\mathrm{d}>\mathrm{b}$, then their linear combination will be $\mathrm{I}(\mathrm{d})$, and if $\mathrm{d}<\mathrm{b}$, then their linear combination will be I(b). It can be concluded that, if variables with different order of integration are combined, the combination will have the order of integration equal to the largest one. 
Furthermore, if we have two series $\mathrm{x}_{1}$ and $\mathrm{x}_{2}$ that are both $\mathrm{I}(1)$, and if we put them in the regression model

$$
y_{t}=\beta_{0}+\beta_{1} x_{1 t}+\beta_{2} x_{2 t}+u_{t}
$$

the third series, variable $y$, will be generated, and it is also I(1). However, there is also a fourth series $u$ (residual), which is desirable (knowing the characteristics of the residuals), to be $\mathrm{I}(0)$. From expression (5), expression

$$
u_{t}=y_{t}-\beta_{0}-\beta_{1} x_{1 t}-\beta_{2} x_{2 t}
$$

can be obtained. If variable $u$ is $\mathrm{I}(0)$ (stationary in levels), it means that original variables $\mathrm{x}_{1}$ and $\mathrm{x}_{2}$ are cointegrated (Brooks, C., 2002, 388).

The above definition of cointegration is the basis for the cointegration test between two variables. Thus it is necessary to test the residuals of (6) to see whether they are non-stationary or stationary. The ADF or PP test can be used on $\mathrm{u}_{t}$ raising the following hypothesis: $\mathrm{H}_{0}: \mathrm{u}_{t} \sim \mathrm{I}(1)$, and $\mathrm{H}_{1}: \mathrm{u}_{t} \sim \mathrm{I}(0)$. So, if we do not reject the null hypothesis, that means there is no cointegration. On the other hand, if the null is rejected, it would be concluded that a stationary combination of the non-stationary variables has been found and thus that the variables are cointegrated.

If we examine cointegration between only two variables, then there can be at most only one linear combination that is stationary, i.e. at most one cointegrating relationship. However, if there are $k$ variables in the system, in this case, there may be up to $r$ linearly independent cointegrating relationships where $r$ $=k-1$. This obviously presents a problem for the above-described approach, because it is capable to determine at most one cointegrating relationship, no matter how many variables there are in the system. The answer to this is to use the Johansen method which is based on the VAR (Vector autoregressive model). The VAR model and Johansen technique are briefly explained below.

Suppose we have $g$ variables $(g=2)$ and that they are all $\mathrm{I}(1)$. It can be fitted $\operatorname{VAR}(\mathrm{k})(7)$ that contains these variables with $\mathrm{k}$ lags: 
$\mathrm{y}_{t} \beta_{1} \mathrm{y}_{t-1} \beta_{2} \mathrm{y}_{t-2} \beta_{k} \mathrm{y}_{t-k} \mathrm{u}_{t}$

$$
\begin{aligned}
& {\left[\begin{array}{c}
y_{1 t} \\
y_{2 t} \\
\vdots \\
y_{g t}
\end{array}\right]=\left[\begin{array}{cccc}
\beta_{111} & \beta_{112} & \ldots & \beta_{11 g} \\
\beta_{211} & \beta_{212} & \ldots & \beta_{21 g} \\
\vdots & \vdots & \vdots & \vdots \\
\beta_{g 11} & \beta_{g 12} & \ldots & \beta_{g 1 g}
\end{array}\right] \cdot\left[\begin{array}{c}
y_{1 t-1} \\
y_{2 t-1} \\
\vdots \\
y_{g t-1}
\end{array}\right]+\left[\begin{array}{cccc}
\beta_{121} & \beta_{122} & \ldots & \beta_{12 g} \\
\beta_{221} & \beta_{222} & \ldots & \beta_{22 g} \\
\vdots & \vdots & \vdots & \vdots \\
\beta_{g 21} & \beta_{g 22} & \ldots & \beta_{g 2 g}
\end{array}\right] .} \\
& {\left[\begin{array}{c}
y_{1 t-2} \\
y_{2 t-2} \\
\vdots \\
y_{g t-2}
\end{array}\right]+\ldots+\left[\begin{array}{cccc}
\beta_{1 k 1} & \beta_{1 k 2} & \ldots & \beta_{1 k g} \\
\beta_{2 k 1} & \beta_{2 k 2} & \ldots & \beta_{2 k g} \\
\vdots & \vdots & \vdots & \vdots \\
\beta_{g k 1} & \beta_{g k 2} & \ldots & \beta_{g k g}
\end{array}\right] \cdot\left[\begin{array}{c}
y_{1 t-k} \\
y_{2 t-k} \\
\vdots \\
y_{g t-k}
\end{array}\right]+\left[\begin{array}{c}
u_{1 t} \\
u_{2 t} \\
\vdots \\
u_{g t}
\end{array}\right]} \\
& \begin{array}{lllll}
(g, 1) & (g, g) & (g, 1) & (g, g)
\end{array}
\end{aligned}
$$

In order to use the Johansen test, the VAR above needs to be turned into a vector error correction model (VECM) (Harris, R., Sollis, R., 2003, 521) of the form:

$$
\Delta y_{t}=\Pi y_{t-k}+\Gamma_{1} \Delta y_{t-1}+\Gamma_{2} \Delta y_{t-2}+\ldots+\Gamma_{k-1} \Delta y_{t-(k-1)}+u t
$$

where $\Pi=\left(\sum_{i=1}^{k} \beta_{i}\right)-I_{g}$, and $\Gamma_{i}=\left(\sum_{j=1}^{i} \beta_{j}\right)-I_{g}\left(\beta_{i}-\right.$ above defined matrix, and $\mathrm{I}_{g}$ unit matrix of order $g$ )

$\Pi$ can be defined as a long-run coefficient matrix since in equilibrium, all the $\Delta \mathrm{y}_{t-i}$ will be zero. Also in a long-run $\mathrm{u}_{t}$ matrix should be equal to zero. The Johansen test centres on an examination of a rank of the $\Pi$ matrix via its eigenvalues. The eigenvalues are put in descending, order: $\lambda_{1} \geq \lambda_{2} \geq \ldots \geq \lambda_{g}$. If time series variables are not cointegrated, the rank of $\Pi$ matrix will not be significantly different from zero, i.e. the number of eigenvalues that are significantly different from zero will be less than the number of variables in the VAR model. The test statistics does not examine $\lambda_{i}$ rather $\ln \left(1-\lambda_{i}\right)$, but still, when $\lambda_{i}=0$ then $\ln \left(1-\lambda_{i}\right)=0$.

In practice two test statistics for cointegration under the Johansen approach are used. These are:

and

$$
\lambda_{\text {trace }}(r)=-T \sum_{i=r+1}^{g} \ln \left(1-\hat{\lambda}_{i}\right)
$$

$$
\lambda_{\max }(r, r+1)=-T \ln \left(1-\hat{\lambda}_{r+1}\right)
$$


Where $r$ is the number of cointegrating vectors under the null hypothesis, and $\lambda_{i}$ is the estimated value for the $\mathrm{i}^{\mathrm{th}}$ ordered eigenvalue from the $\Pi$ matrix. Obviously, the larger $\lambda_{i}$ is, the more negative will be $\ln \left(1-\lambda_{i}\right)$, and therefore larger will be the test statistic.

The expression (9) is a test which uses all eigenvalues jointly and where the null hypothesis is $\mathrm{H}_{0}$ - the number of cointegrating vectors is less than or equal to $r$, and the alternative hypothesis $\left(\mathrm{H}_{1}\right)$ is that this number is greater than $r$. The expression (10) is used on each eigenvalue separately, and has as its null hypothesis that the number of cointegrating vectors is $r$ against an alternative of $r+1$.

If the test statistic is greater than the critical value from Johansen's tables, the null hypothesis is rejected in favour of the alternative hypothesis (in both tests). The testing is conducted in a sequence under the null hypothesis $r=0$, then $r=1, \ldots, r=g-1$. This means that the first null hypothesis assumes that $\Pi$ matrix has rank zero. If this null is not rejected, the conclusion is that there are no cointegrating relationships between the variables of the VAR model and the test is completed. If $\mathrm{H}_{0}$ is rejected, it raises a new $\mathrm{H}_{0}$ hypothesis that examines whether the rank of a $\Pi$ matrix is equal to 1 . If we accept this hypothesis, this means that there is only one cointegrating relationship between variables in the model, etc.

\subsection{DATA}

The input data consist of daily values of the capital market indices of selected CEE countries that joined the EU in 2004, as well as indices of selected countries of old EU member states. The first group contains Slovenian (SBI20), Slovakian (SAX), Czech (PX) and Hungarian (BUX) stock market indices, and the other group contains German (DAX) and UK (FTSE) stock market indices. The analyzed period is from January $2^{\text {nd }}$, 2001 through October $1^{\text {st }}$, 2009. The data sources are the official web sites of the stock exchanges, as well as http://yahoo.finance.com.

There is a huge difference in the degree of development of the underlying stock markets. Observing the value of market capitalization and trade volume, the 
Economic Research - Ekonomska Istrazivanja Vol. 25, SE 1, 2012 Page:324

London Stock Exchange, as the world's leading financial centre beside the New York Stock Exchange, is far ahead of all other analyzed stock markets. That confirms the results of a comparison of market capitalization to GDP ratio, which reveals a significant lag behind of the Bratislava Stock Exchange in relation to other observed exchanges (see table 1).

TABLE 1 The market capitalization to GDP ratio

\begin{tabular}{lccc}
\hline \hline & 2007 & 2008 & 2009 \\
\hline United Kingdom & 1.283 & 0.745 & 1.248 \\
Germany & 0.592 & 0.321 & 0.376 \\
Hungary & 0.313 & 0.125 & 0.225 \\
Slovakia & 0.083 & 0.061 & 0.057 \\
Slovenia & 0.571 & 0.227 & 0.239 \\
Czech Republic & 0.377 & 0.200 & 0.228 \\
\hline \hline
\end{tabular}

Source: Author's calculations based on data from FESE and EUROSTAT

Regarding the trends of the analyzed stock indices, in Figure 1 we can see that all the stock exchange indices in late 2007 registered downwards trends, and that all of them start to recover by the end of 2008, except the Bratislava Stock Exchange index. Of course, the figure also shows that the index of the Bratislava Stock Exchange has entered into its downward trend last, and there is no significant sign of its recovery. 


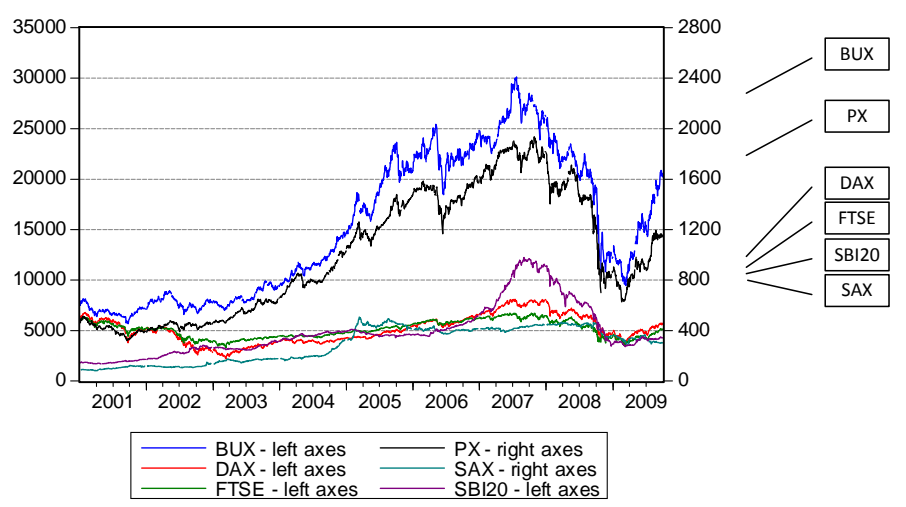

FIGURE 1 The movement of BUX, SAX, SBI20, PX, FTSE i DAX index

Source: www.ljse.si, www.bse.hu, www.bsse.sk, http://www.pse.cz

http://finance.yahoo.com

The following table summarizes the descriptive statistical analysis of stock market indices.

TABLE 2 Summary statistics for stock exchange indices

\begin{tabular}{lcccccc}
\hline \hline & SBI20 & BUX & DAX & FTSE & SAX & PX \\
\hline Mean & $4,901.52$ & $15,219.80$ & $5,116.30$ & $5,122.22$ & 289.78 & $1,004.44$ \\
Median & $4,475.91$ & $13,770.80$ & $4,975.52$ & $5,149.90$ & 329.99 & 901.25 \\
Maximum & $12,242.01$ & $30,118.12$ & $8,105.69$ & $6,732.40$ & 507.98 & $1,936.10$ \\
Minimum & $1,700.24$ & $5,670.98$ & $2,202.96$ & $3,287.00$ & 81.89 & 320.10 \\
Std. Dev. & $2,529.96$ & $6,986.36$ & $1,377.70$ & 834.76 & 138.02 & 486.36 \\
Skewness & 1.24942 & 0.26873 & 0.25898 & 0.05599 & -0.15125 & 0.22808 \\
Kurtosis & 3.99272 & 1.60162 & 2.27435 & 1.83652 & 1.33665 & 1.62427 \\
Jarque-Bera & 656.3913 & 204.5141 & 73.7213 & 125.8073 & 253.0722 & 192.3896 \\
Probability & 0.0000 & 0.0000 & 0.0000 & 0.0000 & 0.0000 & 0.0000 \\
Observations & 2,179 & 2,187 & 2,226 & 2,210 & 2,125 & 2,179 \\
\hline \hline
\end{tabular}

Source: Author's calculation using software package EViews 5.0

From the table, among other things, it can be noticed that the distributions SBI20, BUX, DAX, FTSE and the PX indices have a long right tail, while the distribution of the SAX index has a long left tail.

Tonci Svilokos - CAPITAL MARKET COINTEGRATION OF OLD AND 
In addition, the distributions of BUX, DAX, FTSE PX and SAX are more peaked (leptokurtic) relative to the normal, while the SBI20 distribution is flat (platykurtic) compared to the normal distribution.

Jarque-Bera is a test statistic for testing whether the series is normally distributed. The test statistic measures the difference of the skewness and kurtosis of the series from those of normal distribution. The reported probability is a probability that a critical value of the Jarque-Bera is greater (in absolute terms) than the obtained value. A small probability value leads to the rejection of the null hypothesis of a normal distribution.

Because of a different number of working days, there are a different number of observations for each series.

\section{EMPIRICAL RESULTS}

\subsection{UNIT ROOT TEST}

In order to determine whether the of time series indices are stationary in levels, first differences or even in higher differences, the ADF (Augmented DickeyFuller) and PP (Phillips-Perron) tests are employed. In financial practice, the original series typically contain a unit root, i.e. they are non-stationary in their initial levels, but their differentiation usually gives stationary series.

Table 3 shows the result of the stationary test of daily stock exchange indices in levels. Null hypothesis is set: $\mathrm{H}_{0}$ - series is no stationary (has a unit root). This hypothesis will be accepted if the calculated ADF value is greater than the critical value. As shown in the table, the ADF test and PP test suggest for all variables to accept the $\mathrm{H}_{0}$ hypothesis with a significance level of $5 \%$. In order to avoid autocorrelation of residuals in autoregressive model, lag was selected based upon Akaike information criterion (AIC) and also is given in table 3 . 
Economic Research - Ekonomska Istrazivanja Vol. 25, SE 1, 2012

Page:327

TABLE 3 Unit root tests of daily stock exchange indices in levels

\begin{tabular}{lccccc}
\hline \hline \multicolumn{1}{c}{ Index } & Lag & ADF* & $\begin{array}{c}\text { Critical } \\
\text { value 5\% }\end{array}$ & PP* & $\begin{array}{c}\text { Critical } \\
\text { value 5\% }\end{array}$ \\
\hline BUX & 18 & -1.574382 & -2.863758 & -1.261966 & -2.862651 \\
DAX & 5 & -1.867222 & -2.862755 & -1.545067 & -2.862658 \\
FTSE & 26 & -1.993437 & -2.863890 & -1.802529 & -2.862680 \\
SAX & 5 & -1.453740 & -2.863020 & -1.444428 & -2.862747 \\
SBI20 & 24 & -0.827007 & -2.864679 & -1.205567 & -2.862707 \\
PX & 22 & -0.383822 & -2.863835 & -1.329140 & -2.862692 \\
\hline \hline
\end{tabular}

Source: Author's calculation using software package EViews 5.0

* Note: ADF and PP tests were carried out including the intercept in test equation. The results of the tests that include both, trend and intercept, as well as the tests that do not include any of them, are not presented here. However, they also suggest the same conclusions.

Now, it is necessary to determine whether these series after differentiation become stationary. As in the previous test, the same $\mathrm{H}_{0}$ hypothesis is set: series is no stationary (it has a unit root).

TABLE 4 Unit root tests of daily stock exchange indices - in differences

\begin{tabular}{lccccc}
\hline \hline \multicolumn{1}{c}{ Index } & Lag & ADF* & $\begin{array}{c}\text { Critical value } \\
5 \%\end{array}$ & PP* & $\begin{array}{c}\text { Critical value } \\
5 \%\end{array}$ \\
\hline BUX & 17 & -5.893617 & -2.863758 & -41.91842 & -2.862743 \\
DAX & 4 & -21.14884 & -2.862755 & -48.04267 & -2.862679 \\
FTSE & 25 & -6.748749 & -2.863890 & -49.80626 & -2.862714 \\
SAX & 4 & -15.77284 & -2.863020 & -45.20865 & -2.862799 \\
SBI20 & 23 & -2.871325 & -2.864679 & -33.98671 & -2.862750 \\
PX & 25 & -4.033872 & -2.864174 & -43.13906 & -2.862733 \\
\hline \hline
\end{tabular}

Source: Author's calculation using software package EViews 5.0

* Note: ADF and PP tests were carried out including the intercept in test equation. The results of the tests that include both, trend and intercept, as well as the tests that do not include any of them, are not presented here. However, they also suggest the same conclusions.

Tonci Svilokos - CAPITAL MARKET COINTEGRATION OF OLD AND NEW EU MEMBER STATES 
Table 4 clearly shows that both stationary tests indicate that the first differences of all indices are stationary, i.e. that they are $\mathrm{I}(1)$. These test results are a very important precondition for further modelling of multivariate time series models.

\subsection{STATIC COINTEGRATION ANALYSIS}

For the integration test of selected capital markets of new EU member states and the capital markets of Germany and Britain, two VAR(5) models are set up on which the Johansen cointegration method is applied. This method has emerged as a very powerful technique for examining common trends in multivariate time series and provides a sound methodology for modelling long-run, as well as shortrun dynamics in the system. Cointegration tests allow us to determine whether the stock prices or index values of different national markets move together in the long-run with the possible occasional divergences in the short-run.

The graphs of the stock market indices (see Figure 1) indicate the existence of a deterministic trend component, which was taken into account when selecting the cointegration test specification.

TABLE 5 Testing the cointegration between DAX, BUX, SAX, PX and SBI20 -Johansen cointegration test

\begin{tabular}{|c|c|c|c|c|c|c|}
\hline \multicolumn{7}{|c|}{ Sample (adjusted): 1/15/2001 09/25/2009 } \\
\hline \multicolumn{7}{|c|}{ Included observations: 1398 after adjustments } \\
\hline \multicolumn{7}{|c|}{ Trend assumption: Linear deterministic trend } \\
\hline & \multicolumn{3}{|c|}{ Trace } & \multicolumn{3}{|c|}{ Maximum Eigenvalue } \\
\hline $\begin{array}{c}\text { Maximu } \\
\text { m rank }\end{array}$ & Eigenvalue & $\lambda_{\text {trace }}$ & $\begin{array}{l}0.05 \text { Crit. } \\
\text { Value }\end{array}$ & Eigenvalue & $\lambda_{\max }$ & $\begin{array}{l}0.05 \text { Crit. } \\
\text { Value }\end{array}$ \\
\hline 0 & 0.025149 & 72.27627 & 69.81889 & 0.025149 & 35.60759 & 33.87687 \\
\hline 1 & 0.011250 & 36.66868 & 47.85613 & 0.01125 & 15.81725 & 27.58434 \\
\hline 2 & 0.008557 & 20.85143 & 29.79707 & 0.008557 & 12.01431 & 21.13162 \\
\hline 3 & 0.004528 & 8.837113 & 15.49471 & 0.004528 & 6.345216 & 14.2646 \\
\hline 4 & 0.001781 & 2.491897 & 3.841466 & 0.001781 & 2.491897 & 3.841466 \\
\hline
\end{tabular}

Source: Author's calculation using software package EViews 5.0

Note: $\lambda_{\text {trace }}$ and $\lambda_{\max }$ values that suggest the acceptance of the hypothesis $H_{0}$ are marked in bold

Tonci Svilokos - CAPITAL MARKET COINTEGRATION OF OLD AND NEW EU MEMBER STATES 
TABLE 6 Testing the cointegration between FTSE, BUX, SAX, PX and SBI20 -Johansen cointegration test

\begin{tabular}{|c|c|c|c|c|c|c|}
\hline \multicolumn{7}{|c|}{ Included observations: 1354 after adjustments } \\
\hline \multicolumn{7}{|c|}{ Trend assumption: Linear deterministic trend } \\
\hline \multirow[b]{2}{*}{$\begin{array}{c}\text { Maximu } \\
\text { m rank }\end{array}$} & \multicolumn{3}{|c|}{ Trace } & \multicolumn{3}{|c|}{ Maximum Eigenvalue } \\
\hline & $\begin{array}{c}\text { Eigenvalu } \\
\mathrm{e}\end{array}$ & $\lambda_{\text {trace }}$ & $\begin{array}{l}0.05 \text { Crit. } \\
\text { Value }\end{array}$ & Eigenvalue & $\lambda_{\max }$ & $\begin{array}{l}0.05 \text { Crit. } \\
\text { Value }\end{array}$ \\
\hline 0 & 0.023851 & 63.52327 & 69.81889 & 0.023851 & 32.68610 & 33.87687 \\
\hline 1 & 0.012367 & 30.83717 & 47.85613 & 0.012367 & 16.84918 & 27.58434 \\
\hline 2 & 0.006144 & 13.98799 & 29.79707 & 0.006144 & 8.344082 & 21.13162 \\
\hline 3 & 0.002835 & 5.643904 & 15.49471 & 0.002835 & 3.844527 & 14.26460 \\
\hline 4 & 0.001328 & 1.799377 & 3.841466 & 0.001328 & 1.799377 & 3.841466 \\
\hline
\end{tabular}

Source: Author's calculation using software package EViews 5.0

Note: $\lambda_{\text {trace }}$ and $\lambda_{\max }$ values that suggest the acceptance of the hypothesis $H_{0}$ are marked in bold

The results of the static cointegration tests for $\operatorname{VAR}(? ?)$ multivariate models are presented in Tables No. 5 and 6 (the first test includes the Frankfurt stock exchange index (DAX) and indices of selected CEE stock markets, and the second includes the London Stock Exchange index (FTSE) and indices of selected CEE stock markets). They indicate that the five markets that are set in the first VAR model generated one cointegrating vector, while the second model did not find any cointegrating vector. This result proves the egsistance of global factors, but their strength is still not enough to be able to conclude that there is a complete cointegration between the capital market of new and old member states. The existence of one cointegrating vector suggests that future fluctuations of stock indices in one market can be determined or predicted to some extent using the information set provided by the other stock price indices. The presence of equilibrium relationships could be partly attributed to the gradual harmonization of CEE economies with those of the developed EU countries. External forces such as a common commercial policy within the EU, especially common monetary policy for countries in the EMU, have an influence on markets by focusing them towards long-run equilibrium. 
Economic Research - Ekonomska Istrazivanja Vol. 25, SE 1, 2012

Page:330

The dynamics of the integration of capital markets are investigated below.

\subsection{DYNAMIC COINTEGRATION ANALYSIS}

The purpose of the third part of this empirical research is to determine the underlying dynamics of the capital markets integration process. Two approaches are employed: recursive cointegration and a rolling-window approach.

In the first method, the Johansen test is calculated over an initial estimation period $t$ which is gradually extended to estimation period $t+i$, then the Johansen test is calculated again.

In the second approach, the estimation window with fixed length (called a rolling-window) was chosen, and it "rolls forward" over time (always retaining its fixed size).

In the first case, daily values of the stock indices from January 2001 to December 2002 were chosen for the initial estimation window, and it is extended for sixmonth increments, while in the second approach the initial estimation window is the same (January 2001 - December 2002), but it moves six month forward at a time (retaining its fixed length). In both approaches the Johansen test

calculates the relevant $\lambda_{\text {trace }}$ value. The results are presented in Tables 7 and 8. 
Economic Research - Ekonomska Istrazivanja Vol. 25, SE 1, 2012

Page:331

TABLE 7 Dynamic cointegration analysis of DAX, BUX, SAX, PX and SBI20 indices - Johansen cointegration test

\begin{tabular}{|c|c|c|c|c|c|c|}
\hline \multirow[b]{3}{*}{$2001 / 02$} & \multicolumn{3}{|c|}{ Recursive cointegration approach } & \multicolumn{3}{|c|}{ Rolling-window approach } \\
\hline & Observations & $\lambda_{\text {trace }}$ & $\mathrm{P}$ & Observations & $\lambda_{\text {trace }}$ & $\mathrm{p}$ \\
\hline & 317 & 45.55772 & 0.8126 & 317 & 45.55772 & 0.8126 \\
\hline 2003 I & 398 & 50.36924 & 0.6216 & 332 & 46.06004 & 0.7953 \\
\hline 2003 II & 489 & 34.89492 & 0.9913 & 340 & 25.67853 & 1.0000 \\
\hline 2004 I & 568 & 36.59274 & 0.9829 & 355 & 36.28695 & 0.9848 \\
\hline 2004 II & 657 & 38.08201 & 0.9120 & 340 & 33.74355 & 0.9948 \\
\hline $2005 \mathrm{I}$ & 720 & 47.47876 & 0.7425 & 322 & 59.21962 & 0.2601 \\
\hline 2005 II & 806 & 40.00285 & 0.9476 & 317 & 31.15369 & 0.9986 \\
\hline 2006 I & 873 & 47.88077 & 0.7266 & 305 & 40.41429 & 0.9411 \\
\hline 2006 II & 954 & 60.62958 & 0.2165 & 297 & 54.16194 & 0.4546 \\
\hline 2007 I & 1016 & 77.29102 & 0.0112 & 297 & 65.46394 & 0.1059 \\
\hline 2007 II & 1111 & 60.55810 & 0.2186 & 305 & 52.53185 & 0.5259 \\
\hline $2008 \mathrm{I}$ & 1179 & 73.30100 & 0.0257 & 307 & 73.89644 & 0.0228 \\
\hline 2008 II & 1280 & 76.64342 & 0.0129 & 326 & 68.43090 & 0.0642 \\
\hline $2009 \mathrm{I}$ & 1350 & 74.79573 & 0.0190 & 334 & 74.95636 & 0.0183 \\
\hline 2009 II & 1398 & 72.27627 & 0.0314 & 287 & 62.06421 & 0.1775 \\
\hline
\end{tabular}

Source: Author's calculation using software package EViews 5.0

Note: Critical $\lambda$ value for significance level of $10 \%$ is 65.81970, and for significance level of $5 \%$ is 69.81889

TABLE 8 Dynamic cointegration analysis of FTSE, BUX, SAX, PX and SBI20 indices - Johansen cointegration test

\begin{tabular}{|c|c|c|c|c|c|c|}
\hline & \multicolumn{3}{|c|}{ Recursive cointegration approach } & \multicolumn{3}{|c|}{ Rolling-window approach } \\
\hline & Observations & $\lambda_{\text {trace }}$ & $\mathrm{P}$ & Observations & $\lambda_{\text {trace }}$ & $\mathrm{p}$ \\
\hline $2001 / 02$ & 303 & 42.15376 & 0.9078 & 303 & 42.15376 & 0.9078 \\
\hline 2003 I & 379 & 46.51670 & 0.7789 & 317 & 45.75135 & 0.8060 \\
\hline 2003 II & 468 & 34.40252 & 0.9930 & 325 & 28.80263 & 0.9997 \\
\hline 2004 I & 543 & 44.65126 & 0.8418 & 336 & 47.10218 & 0.7570 \\
\hline 2004 II & 630 & 45.24442 & 0.8230 & 327 & 42.99897 & 0.8879 \\
\hline 2005 I & 690 & 52.52095 & 0.5264 & 311 & 54.27479 & 0.4497 \\
\hline 2005 II & 776 & 37.49410 & 0.9763 & 308 & 28.65074 & 0.9997 \\
\hline $2006 \mathrm{I}$ & 839 & 43.59670 & 0.8723 & 296 & 33.92883 & 0.9944 \\
\hline 2006 II & 918 & 57.48513 & 0.3206 & 288 & 46.29619 & 0.7869 \\
\hline 2007 I & 980 & 76.38635 & 0.0136 & 290 & 64.73901 & 0.1189 \\
\hline 2007 II & 1074 & 55.49603 & 0.3985 & 298 & 48.53726 & 0.6999 \\
\hline 2008 I & 1137 & 65.91074 & 0.0985 & 298 & 63.71548 & 0.1393 \\
\hline $2008 \mathrm{II}$ & 1236 & 69.62687 & 0.0518 & 318 & 62.19988 & 0.1741 \\
\hline 2009 I & 1307 & 68.48981 & 0.0635 & 327 & 69.94843 & 0.0488 \\
\hline 2009 II & 1354 & 63.52327 & 0.1434 & 280 & 47.57898 & 0.7386 \\
\hline
\end{tabular}

Source: Author's calculation using software package EViews 5.0

Note: Critical $\lambda$ value for significance level of $10 \%$ is 65.81970 , and for significance level of $5 \%$ is 69.81889

Tonci Svilokos - CAPITAL MARKET COINTEGRATION OF OLD AND NEW EU MEMBER STATES 
Due to easier interpretation of the results, the calculated value of $\lambda_{\text {trace }}$ is rescaled to a critical value $(1.0=90 \%)$. The direction of movement of the presented graphs indicates an increase/decrease level of integration of the respective capital markets (see Figures 2 and 3 ).

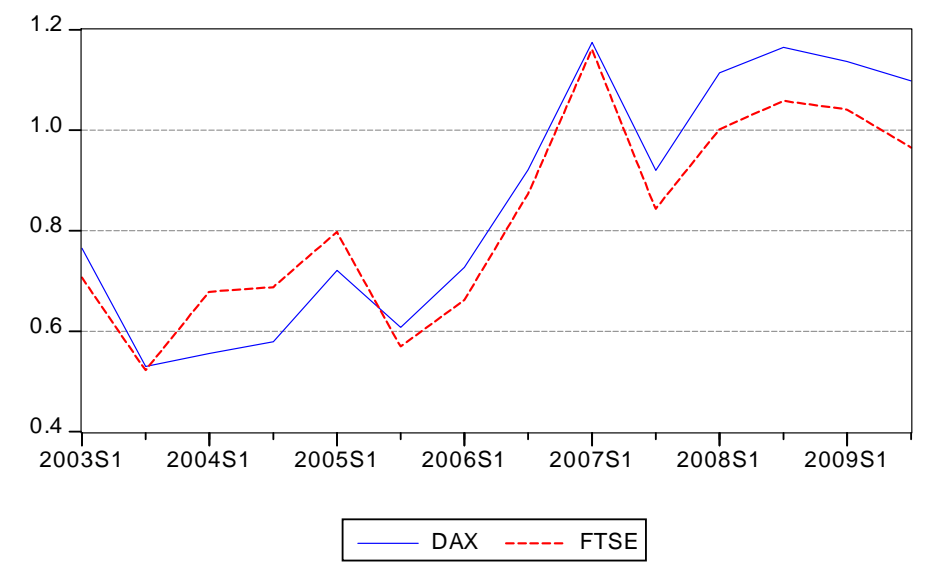

FIGURE 2 Recursive $\lambda_{\text {trace }}$ statistic rescaled to a critical value - significance level $10 \%$

Source: Author's calculation based on the data from tables 7 and 8

When the rescaled lambda trace graph is in a growing trend this suggests increasing levels of integration, while the downward trend indicates a reduction of integration of respective markets. Figures 2 and 3 show the evolution of the $\lambda_{\text {trace }}$ statistic for two multivariate $\operatorname{VAR}(? ?)$ models. One includes stock market indices of selected new EU member states (Slovenia, Hungary, the Czech Republic and Slovakia) in relation to the German stock market index, while the second contains the same indices of new EU member states in relation to the UK stock market index. Lambda trace values are similar in both models, however, a slightly higher degree of integration of capital markets of new EU member states has been recorded in relation to the German capital market than in relation to the London capital market, after mid-2005.

It is evident that there are periods of time when the normalized $\lambda_{\text {trace }}$ value is less than the $90 \%$ of critical value (below 1 in the graphs), but the figures show 
a trend of increasing levels of integration from the end of 2003 to the first half of 2008 (As shown in the graph in Figure 2), or until early 2009 (according to the graph in Figure 3).

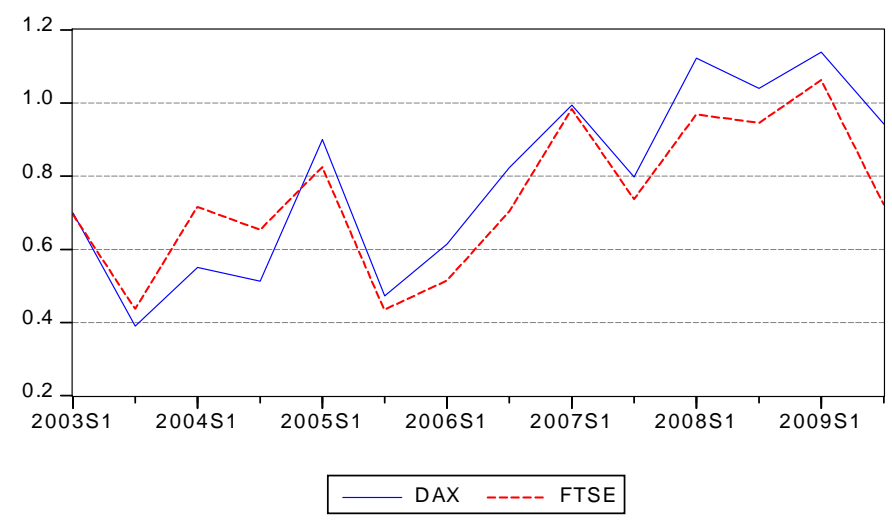

FIGURE 3 Rolling-Window $\lambda_{\text {trace }}$ statistic rescaled to a critical value - significance level $10 \%$

Source: Author's calculation based on the data from tables 7 and 8 There are several possible theoretical explanations for the increasing level of capital markets integration:

1. The joining of the CEE countries to the EU (2004) increases liberalization of capital movements and reduces barriers to its circulation

2. Trade ties between the old and new EU member states are strengthening

3. Entry of old EU member countries' banks into the banking systems of Central and East Europe countries could have made these markets more co-ordinated and integrated (Schmitz, 2004). This is very important since banks are the single biggest players in emerging countries' equity markets

4. The two analyzed countries (Slovenia since 2007 and Slovakia since 2009) are members of the EMU, which means that they are under the influence of a common European monetary policy. 
If we start from the fact that the consequences of the global financial crisis manifested in European financial markets from the second half of 2007, and that the recovery of the market (in most cases) followed in the first half of 2009, (See Figure 1), and if we take a look at that period in Figures 2 and 3 , we can come to the conclusion that the beginning of the financial crisis was accompanied by reduced levels of co-integration. However, in 2008 when market indices are still in downward direction, the degree of cointegration increased. An explanation for this can be found in the fact that all countries did not enter into a recession at the same time, nor their declines were the same.

Furthermore, due to the unequal market recovery in 2009 (Slovak capital market, according to SAX has not started its recovery yet) a reduced level of cointegration was found, which means that in this period, local factors that affect the global price trends prevailed.

\section{CONCLUSION}

A very important characteristic of financial globalization in the EU, is the strengthening of economic linkages between member countries. They are becoming more and more integrated, as a result of the growth of international trade, banking acquisitions in the CEE, as well as the enlargement of the Monetary Union.

International portfolio diversification is less effective across the cointegrated markets, as investment risk cannot be reduced, and portfolio returns can exhibit similar reactions to internal and external shocks. Cointegrated stock indices converge towards a common long-run equilibrium path, as macroeconomic policies in the EU are striving to be more coordinated. Because of this, foreign investors have started to consider EU capital markets as one market.

This study reveals a growing trend of integration level between new and old capital markets of the European Union. CE Capital Markets (Slovenian, Hungarian, Slovak and Czech) and German capital markets share one cointegrating vector which suggests that future price fluctuations in one market could be determined or predicted to some extent by using the information set provided by 
the other stock price indices. The static cointegration analysis suggests that integration is to some extent present, it increases, but certainly it cannot be concluded that there is a complete cointegration between capital markets.

The financial crisis was manifested on analysed equity markets at different moments in time and intensity, and countries start to recover from the crisis at different times and speeds. Because of this, the results obtained from the dynamic cointegration analysis did not show a significant increase (or decrease) of financial integration in the period from the second half of 2007 to the first half of 2009 .

\section{REFERENCES}

Brooks, C. (2002): Introductory Econometrics for Finance, Cambridge University press

Charemza, W. W., Deadman, D. F. (1997): New Directions in Econometric Practice, Cheltenham: Edward Elgar

Dekker, A. K., Sen. K., Young, M. (2001): Equity Market in the Asia Pacific Region: A Comparison of the Orthogonalized and Generalized VAR Approaches, Global Finance Journal, 12, pp. 1057 - 1072

Dickey, D. A., Fuller. W. A. (1979): Distribution of Estimators for Time Series Regressions with a Unit Root, Journal of the American Statistical Association, Vol. 74, No. 366, pp. $427-431$

Egert, B., Koèenda, E. (2007): Interdependence Between Eastern and Western European Stock Markets: Evidence from Intraday Data", Economic Systems 31, pp. $184-203$

Engle, R. F., \& Granger, C. W. J. (1987): Co-integration and Error Correction: Representation, Estimation and Testing, Econometrica, 55, pp. $251-276$

Fratzscher, M. (2001): Financial Market Integration in Europe: on the Effects of EMU on Stock Markets, ECB Working Paper Series European Central Bank no. 48, pp. $5-41$ 
Gilmore, G. C, Lucey, M. B., MacManus, M. G. (2008): The Dynamics of Central European Equity Market Comovements, The Quarterly Review of Economics and Finance, 48, pp. $605-622$

Hardouvelis, G., Malliaropulos, D., Priestly, R. (1999): EMU and European Stock Market Integration, CEPR Discussion Paper No. 2124. London, Centre for Economic Policy Research. http://www.cepr.org/pubs/dps/DP2124.asp (accessed 5 September 2010)

Harris, R., Sollis, R., (2003): Applied Time Series Modelling and Forecasting, John Viley and Sons

Ip-Wing Yu, Kang-Por Fung, Chi-Sang Tam, (2010): Assessing Financial Market Integration in Asia - Equity Markets, Journal of Banking \& Finance (2010), doi:10.1016/j.jbankfin.2010.02.010.

Johansen, S. (1988): Statistical Analysis of Cointegration Vectors, Journal of Economic Dynamics and Control, 12, pp. 231-254

Kim, S. J., Moshirian, F., Wu, E. (2005): Dynamic Stock Market Integration Driven by the European Monetary Union: an Empirical Analysis, Journal of Banking \& Finance, 29, pp. $2475-2502$

Sharma, S. C., \& Wongbangpo, P. (2002): Long Term Trends and Cycles in ASEAN Stock Markets, Review of Financial Economics, 111, pp. 299 315

Schmitz, B. (2004): What Role do Banks play in Monetary Policy Transmission in EU New Member Countries?, in $3^{\text {rd }}$ Macroeconomic Policy Research Workshop, Central Bank of Hungary, pp. 1 - 34 http://www.mnb.hu/Root/

Dokumentumtar/MNB/Kutatas/mnbhu_konf_fomenu/mnbhu_konf0410/ schmitz.pdf (accessed 15 August 2010)

Syriopoulos, T. (2007): Dynamic Linkages Between Emerging European and Developed Stock Markets: Has the EMU any Impact?, International Review of Financial Analysis, 16 (2007) 41 - 60

Vizek, M., Dadiæ, T. (2006): Integration of Croatian, CEE and EU Equity Markets: Cointegration Approach, Ekonomski pregled, 57 (9-10), pp. $631-646$ 